\title{
STS and Enhancement Technologies: A Programme for Future Research
}

\author{
Michael Morrison
}

The concept of human technological enhancement originated as a tool for the moral classification of technologies, but has since spilled over from ethical debates to become a site for prospective technology development as part of a 'converging technologies' agenda. To date, enhancement and the technologies labelled as 'enhancing' have been underserved by STS research. While case studies do exist, there has been a dearth of co-ordinated investigation. This paper proposes a systemic programme for STS research on enhancement technologies based on five key challenges posed by dominant conceptions of enhancement as a way of understanding technological development. After setting out this agenda, a short history of the enhancement debate is provided to illustrate the changing meanings of 'enhancement' across different contexts. Recognising the limitations of critique alone, particular emphasis is given to the possibilities for productive engagement by STS scholars with the domain of enhancement across its multiple manifestations.

Keywords: bioethics, biotechnology, expectations

Enhance, v. Pronunciation: /\&n'ho:ns/ /-'hæns/

To exalt in dignity, rank, estimation, or wealth.

To elevate spiritually or morally.

To lift up with pride; refl. to exalt oneself, assume superiority.

To praise, extol.

To raise in degree, heighten, intensify (qualities, states, powers, etc.).

To magnify subjectively, make to appear greater; to heighten, exaggerate.

To raise (prices, value); to increase (charges, etc.).
To raise or increase in price, value, importance, attractiveness, etc. (Oxford English Dictionary Online, 2013).

The term enhancement is usually used in bioethics to characterise interventions designed to improve human form or functioning beyond what is necessary to sustain or restore good health (Juengst, 1998: 29).

\section{Introduction: What Is Enhancement?}

In a broad sense, as reflected in the Oxford English Dictionary definitions listed above, the idea of enhancement can relate to any improvement (or indeed projected 
improvement) in the circumstances and quality of human lives individually and collectively. The second quote, from the philosopher and bioethicist Eric T. Juengst (1998: 29), captures a second, narrower and more recent conception of 'human enhancement'. Enhancement in this sense refers specifically to the idea that biomedical technologies can be, and are being, used to advance human performance and boost the physical and mental capacities of individuals in ways that go 'beyond what is 'normal' or necessary for life and well-being' (Hogle, 2005: 695). Emerging in the latter decades of the twentieth century, this concept of human enhancement can be read as a response to concerns about the transformative power of biomedical technologies extending into ever greater areas of human life in ways that trouble commonplace human values and norms. In this, there are at least superficial similarities with the sociological concept of medicalisation (Conrad, 2005). Enhancement, however, has its origins in the discipline of bioethics and was initially developed as a tool for moral evaluations of gene therapy. In the original framing, enhancement uses of technology are understood in direct opposition to therapeutic usage, where 'therapy' is taken to describe the commonplace use of medical technologies to treat and manage disease. In this formulation, therapy is always morally legitimate while enhancement applications of technology, by transgressing the remit of therapy, are prima facie ethically suspect (President's Council on Bioethics, 2003). Since that initial formulation, the concept of enhancement has expanded to cover a wider range of technologies and perspectives, becoming a 'standard rhetorical tool' in academic bioethics (Juengst, 1997: 125). The nature of debate has also transformed to include arguments strongly in favour of utilising enhancement technologies for human benefit.
It is likely that most readers will be familiar with at least one, and probably several examples of 'human enhancement technologies', as they are often attract considerable public and media discussion. Some, such as cosmetic surgery (appearance enhancement), have been in existence for many years and have become common, if not entirely uncontested, phenomena. Similarly, pharmaceutical doping in sport, from the use of amphetamines in track and field events during the 1950s to contemporary cyclists taking the anaemia treatment erythropoietin (EPO) to increase their red blood cell count (athletic enhancement), is a recurring issue in professional sports (Wailoo, 2007). More recently, certain blockbuster pharmaceuticals such as Prozac and Viagra, are said to have stretched the definition of illness to become 'enhancements', where, for example, Prozac is claimed not only to treat clinical depression but also to alleviate unhappiness (mood enhancement), making recipients 'better than well' (Rothman, 1994; Wright, 1994). In addition to these well-known examples, the full range of technological options for enhancement includes human genetic engineering, nanotechnology, cognitive and neurological enhancement, regenerative medicine and human-machine interfaces (Hogle, 2005; Miller \& Wilsdon, 2006; Hughes, 2007).

To date the topic of enhancement has been somewhat neglected by scholars in the fields of STS and the sociology of technology. There are of course exceptions (see for example Nordmann, 2004, 2009; Banse et al., 2007; Ferrari, 2008; Morrison, 2008; Roco, 2008; Fuller, 2009, 2011; Coveney, 2010, 2011; Roco \& Bainbridge, 2013; see also Hogle, 2005 for an anthropological perspective), but these have largely been isolated contributions and there has been little concerted attempt to systematically address and investigate enhancement as a 
topic in its own right. Some attention has been given to enhancement through the lens of medicalisation theory (Conrad \& Potter, 2004; Conrad, 2005). While this has yielded some useful insights, it suffers the drawback of ultimately regarding enhancement as yet another avenue for defining social problems in medical terms and proposing medical solutions - in other words the drivers may change but essentially it is regarded as a case of 'medicalisation as usual'. As such, this approach fails to address in depth the dynamics and the substantive content of 'enhancement' as a specific concept and as a means of technological classification. I believe that a comprehensive, integrated programme of research is needed to address the range of different technologies and different contexts of the enhancement debate and that such an approach is capable of generating a deeper and ultimately more productive account of enhancement than one-off studies.

The aim of this paper is twofold: Firstly, I will outline an agenda for a programme of STS research on human enhancement and human enhancement technologies. I use the phrase 'human enhancement and human enhancement technologies' deliberately to indicate the requirement for simultaneous investigation of both technologies labelled as 'enhancements' and the concept of enhancement itself as part of this programme. The context and content, of the term 'human enhancement technology' has changed even over the relatively short course of its history, as has the range of technologies involved. The second contribution of this paper will therefore be to sketch a brief account of the changing dynamics of enhancement from its origins in North-American gene therapy debates to the converging technologies agenda discussed below.

\section{Why Do We Need an STS Approach to Human Enhancement?}

In order to answer this question, we first need to consider what an 'STS approach' or an 'STS perspective' entails. Woolgar et al. (2009: 21) advise that 'it is unhelpful to construe STS as a unitary set of approaches, methods and topics.' Despite this, those same authors also recognise the necessity of having a tolerable 'shorthand' answer to this question and propose the following five 'key STS sensibilities':

1) a propensity to cause trou-

ble, provoke, be awkward

2) a tendency to work through difficult conceptual issues in relation to specific empirical cases, deflating grandiose theoretical concepts and claims (and even some ordinary ones)

3) an emphasis on the local, specific and contingent in relation to the genesis and use of science and technology

4) caution about the unreflexive adoption and deployment of standard social science lexicons (e.g. power, culture, meaning, value)

5) reflexive attention to the (frequently unexplicated) notions of our audiences, value and utility (Woolgar et al., 2009: 21-22)

While I am broadly in agreement with this list, it should be remembered that it was developed in the context of presenting or explaining the 'essence' of STS for utilisation in management and business studies. The topic of biomedical enhancement is rather closer to STS' 'home turf' of the study of science and technology. For the purposes of this paper then, a useful 'shorthand' version of an STS perspective reads more like a truncated summary of the foundational themes of STS, than the characteristics and sensibilities of STS listed by Woolgar et al. 
(2009). It is a crude summary to be sure and fails to address the heterogeneity of perspectives and concepts within the field, but it should suffice for what is needed here.

Broadly, I construe an STS perspective as encompassing a rejection of technological determinism, an insistence on the local and contingent nature of the production of facts and artefacts, and a constructionist approach that takes materiality seriously. Such an approach means rejecting both technological and social determinism as explanations for the development, acceptance or rejection and modes of use of technologies (Timmermans \& Berg, 2003). Material entities - in the case of enhancement the most relevant materialities are those of bodies and technologies - are neither reducible to what is said about them, nor wholly separable from the discourses through which they are mobilised. Rather the 'natural' and 'cultural' are mutually constitutive. To relate this perspective more directly to issues of human biotechnology and biomedicine I will borrow a concept from the anthropology of pharmaceuticals. Nichter \& Vuckovitch (1994) proposed that medicines can be regarded as 'vehicles of ideology': that is, they are not just material entities but embody ideas about the kind of bodies that they are interacting with, about the type of individual taking the medicine, about the condition being targeted, about individual and social responsibility and entitlement, and about what is normal and desirable. While not all cases labelled as 'enhancement' involve pharmaceuticals, all cases of enhancement do involve some form of technological manipulation of human bodies, thus giving reasonable grounds to expand this anthropological perspective to cover 'enhancements'. Enhancement technologies, whether 'bio,' 'nano,' 'neuro' or information/communication technologies, are intended to act on (and in) human bodies and are bound up with ideas such as the nature of those bodies, the end users of the technologies, entitlement, normality and desirability. An STS perspective can serve in the first part to make this entanglement explicit.

In addition, much of the bioethical debate on enhancement to date has been dominated by arguments informed by traditions of (Anglo-American) analytic philosophy such as utilitarian and consequentialist ethics. These approaches to applied ethics tend to incorporate a number of characteristics that are highly problematic from the aforementioned STS perspective. Enhancement readily presents a set of 'grandiose theoretical concepts and claims' (Woolgar et al., 2009: 21-22) that are ripe for critical investigation through case studies of the technologies and practices involved. My first argument in support of an STS engagement with enhancement technologies will therefore highlight in more detail these problematic aspects of the concept of enhancement - specifically various forms of determinism and dualism.

As with all areas of contemporary social science, STS scholars are increasingly directed to pay attention to the issues of value, utility and indeed, audience for their work, as raised in the final point in the list produced by Woolgar et al. (2009). With this in mind, my second argument for the value of a programme of STS work on enhancement technologies focuses on the emergence of technological enhancement as a domain for prospective investment of capital and strategic technology development. This domain suggests a particular audience for STS research in the form of science policy makers, futurologists, and technology developers and has the potential utility of informing decisions about investment in human biological enhancement as a domain of strategic techno-science. I will return to this point 
in subsequent sections to flesh out the argument that this aspect of enhancement offers a site for constructive work in STS that goes beyond critique and 'causing trouble.'

\section{Problems of Determinism and Dualism}

Much of the ethical literature takes the appropriate starting point for (moral) discussion and categorisation of technologies as the moment when a new technology becomes available for application. New technologies though, do not simply arise fully-formed to present ethical dilemmas about their use. Instead, they are shaped by both material factors and the interests and perspectives of social actors involved in the processes of technological creation, regulation and use (Bijker et al., 1987; MacKenzie \& Wajcman, 1999). By excluding from consideration the history, context and politics of technology development, many bioethical approaches implicitly effect a kind of technological determinism that produces a limited debate about the 'good' and 'bad' uses of 'neutral' technologies that come into being more or less directly as products of scientific rationality alone. A case in point is the use of human growth hormone (hGH) to increase the height of short children. Bioethical analyses of the appropriateness of using hGH such as Tauer (1995) and Daniels (1992) frame the issue as a dichotomy between using hGH to treat growth hormone deficient children (acceptable therapy) and giving hGH to 'short normal' children as a means of increasing their final adult height (illegitimate enhancement). Alternatively, an STS-influenced historical approach to the case of hGH, (Morrison, 2008) began by enquiring how childhood stature came to be understood as a treatable condition in the first instance. Without starting from the premise that some uses were intrinsically appropriate or inappropriate, it was possible to derive a socio-technical account of how certain applications (diagnostic categories) came to be legitimated (or find a viable technological niche) while others remained contested (failed to attain closure) as a result of shifting social, material, economic and regulatory relations during the course of the drug's career.

Additionally, certain forms of applied ethical argument common in the enhancement debate unproblematically incorporate the strong nature/culture dualism that pervades their analytic heritage (Twine, 2005; Mills 2010; see also Latour, 1993). Dualistic accounts regard material elements, including both technologies and bodies as belonging solely to the 'natural' and being entirely distinct from 'culture'. This dichotomy places knowledge production in the natural sciences as unproblematic, arising positivistically as an unmediated account of physical reality, while the cultural and historical situatedness of meanings and values given to bodies and technologies is occluded or framed as external to technology itself. Such explanations posit enhancement technologies as a problem (or an opportunity) for society but one driven by a medicine and technology that are seen as separate and distinct from the social realm. An extreme example of this can be found in the work of Daniels (2000), which is discussed further in a subsequent section of this paper. For the most part, a dualistic approach is 'neither a conspiracy theory nor simplistically a pernicious or conscious trend' (Twine, 2005: 289). Rather it is more akin to MacKenzie's (1990) concept of the 'uncertainty trough' where the more removed actors are from the site of technology production the more certainty they tend to attribute to the capabilities of new technological products and projects.

Consider the following accounts by Kass (2003) and Sandel (2004). Both argue against the moral permissibility of enhancement 
per se and both mobilise a distinction between therapeutic applications of biotechnology and 'non-medical ends'. For Sandel (2004: 6), medical/therapeutic use of technology is such that it 'does not desecrate nature but honours it', while nontherapeutic or enhancing applications are clearly identified as being driven by cultural trends and demands for material and social success. 'Socially motivated' applications of biotechnology are regarded as 'serving ends that range from the frivolous and disquieting to the offensive and pernicious' (Kass, 2003: 9).

In a pro-enhancement account from the same time period, Bostrom (2003: 498) argues that genetic enhancement can deliver socially desirable ends ranging from freedom from genetic disease to faster learning, improved immune capabilities, and '[h]ealthier, wittier, happier people'. Responding to (consequentialist) antienhancement arguments, Bostrom (2003) goes on to discuss potential negative outcomes of genetic enhancement, such as the possibility that parents of genetically modified babies would come to regard their offspring more as consumer products and less as individuals valued in their own right, or that availability of enhancements would exacerbate social inequalities. Tellingly, his proposed solutions also involve social (political and economic) interventions such as subsidising enhancements for those with lower socio-economic status or more education to avoid public belief in genetic determinism.

These examples illustrate how, in both pro and anti-enhancement arguments, questions of scientific uncertainty, of how enhancement technologies might be configured in practice, and of the limitations of representing traits like intelligence as biological processes are occluded. Thus content of the technologies is left unexamined, while the potential problems raised by the availability of enhancement technologies and their proposed solutions belong instead to the separate domain of the social.

This widespread unwillingness or inability to recognise the cultural, valueladen aspects of knowledge-production in the natural sciences also means that the promissory, speculative visions of control promulgated by new domains of technoscientific practice (e.g. neuroscience, nanotechnology) tend to be uncritically received by many bioethicists (Hedgecoe, 2004; Melo-Martin, 2005). This in turn often leads to a tacit acceptance of the reductionism involved when socially meaningful concepts such as personality, intelligence or altruism are reconfigured as mere outputs of variations in the functioning of biological components, as, for example, in discussions of genetic engineering to produce individuals with more desirable personality traits or who are better moral actors (Melo-Martin, 2005; see also Dickenson, 2013 chapter 5 for a review of debates on moral enhancement).

\section{The Converging Technologies Agenda}

A second reason why human enhancement technologies warrant greater critical investigation from STS and related fields is that over the past decade the concept of human technological enhancement has spread - spilled over or escaped from the bounds of academic bioethics to become the subject of social movements such as transhumanism (Agar, 2004; Bostrom, 2003), and future-orientated discourses of innovation policy and speculative investment. The latter aspect is most relevant to my proposed agenda for STS, as it brings enhancement into the realm of national and international regimes of economic operation, strategic management and the generation of technoscientific expectations. The first, 
and arguably most significant, articulation of a strategic vision for enhancement technologies was conveyed in the report 'Converging technologies for improving human performance: Nanotechnology, Biotechnology, Information technology and Cognitive science' edited by Roco and Bainbridge (2003) for the US National Science Foundation (NSF) (Fuller, 2009). The report argues for the combination, or convergence, of the four domains of science listed in the report's title in order to yield:

[T] he potential to enhance both human performance and the nation's productivity. Examples of payoffs will include improving work efficiency and learning, enhancing individual sensory and cognitive capabilities, fundamentally new manufacturing processes and improved products [and], revolutionary changes in healthcare (Roco \& Bainbridge, 2003: $1)$.

In the wake of the NSF report, there have been a number of European responses in the form of reports and assessments from the European Union High Level Expert Group on the New Technology Wave (Nordmann, 2004), the Science and Technology Options Assessment (STOA) group of the European Parliament (STOA, 2006, 2012) and direction to issues of biomedical enhancement in several research projects funded through the European Commission's sixth and seventh Framework Programmes (DEEPEN; ENAHNCE; EPOCH; ETHENTECH and FABRICED among others). The potential of enhancement technologies also continues to elicit national responses, as with the recent joint workshop on 'Human enhancement and the future of work' jointly hosted by the Academy of Medical Sciences, the British Academy, the Royal Academy of Engineering and the Royal Society in the UK (2012).
The relatively high-level policy consideration of enhancement technologies as a strategic domain of technoscientific investment and research has at least the potential to transform enhancement from being the topic of a primarily academic debate into a potential stimulus for economic and practical action. What is said about the future matters because:

The rhetoric that surrounds [new technologies] produces imagined futures, while concrete technological practices have the power to produce very real futures materially. Moreover, the rhetorical construction of future worlds directly (and indirectly) influences which technologies are brought into existence by, for example, providing justifications for funding, rallying public support, instigating policy directives, etc. (Selin, 2008: 1879)

And yet, as I will attempt to argue in the course of this paper, the concept of human enhancement technology still contains many of the problematic assumptions about technology congruent with its bioethical origins. It is for these reasons of the problematic nature and increased visibility of the concept of human enhancement technologies that I believe greater STS attention is warranted.

\section{What Does an STS Approach to Enhancement Look Like?}

Given that human biomedical enhancement is both a (changing) concept and a label applied to certain technologies or uses of technologies, an adequate STS approach must engage with both these aspects of the phenomenon. In part, this can be done by drawing on one of the traditional strengths of the field and carrying out empirical case studies of technologies, or technological 
applications, labelled as enhancements. However, before they can be used to critique it, case studies will first need to engage with extant understandings of the concept of enhancement. In doing so, researchers need to avoid the twin perils of uncritically accepting problematic understandings of technology such as nature/culture dualism and of unwittingly finding themselves drawn into the increasingly polarised moral arguments for and against permitting human enhancement technologies. An STS approach must adopt a critical distance from the enhancement debate, taking the concept of enhancement as a topic of investigation rather than a given 'fact' about the technologies and accounts being studied.

\section{Researching Enhancement as a Concept}

One model that could be usefully copied here is Rappert's (2007) work on the issue of 'dual use' research in the context of biological security. The dual use debate concerns whether, and how, it might be possible to identify scientific research intended for beneficial, often biomedical, applications that might also enable the construction of biological weapons or other undesirable hazards. Although dual use research and enhancement derive from different historical and political contexts, both debates concern attempts to classify bio-scientific outputs as acceptable or unacceptable based on criteria other than the scientific quality of the output itself and both are amenable to similar sorts of critical analysis. Rappert (2007) sets out an investigative agenda for dual use research that does not try to resolve the problem as presented, but begins by addressing the terms on which the debate is being conducted. In this work, Rappert (2007) asks what claims are being made about dual use research and how. How are assessments being made and who makes them (and who is excluded)? What assumptions are built in to starting points of the discussion? What other questions can be asked and how should we ask them?

Such an agenda, applied to the study of human enhancement means not taking the category of 'enhancement' (or 'therapy') at face value, but treating it as a claim made by bioethicists and others through the exercise of professional expertise. To inform their case studies, STS scholars must therefore also trace and account for the shifting meanings of enhancement across contexts from bioethics literature to strategic technology evaluations, and unpack the underlying normative commitments in accounts of human technological enhancement. Thus the first component of an STS agenda for studying enhancement technologies should be:

1) To map out the changing landscape of the enhancement debate(s) from its bioethical origins to the present converging technologies agenda.

At this juncture, it is helpful to recall some lessons from sociological engagements with bioethics. Certain sociological accounts of bioethics, in tending to portray all bioethical decisions, texts and forms as part of a single, principle-based bioethical orthodoxy have historically caused friction between the two disciplines (De Vries et al., 2006). It is pertinent to recognise that bioethics, as a fundamentally interdisciplinary enterprise - the field was primarily founded by collaboration between philosophers, theologians and concerned physicians - is not a monolithic entity but rather incorporates a plurality of views and approaches as befits the diversity of bioethicists (De Vries et al., 2006; Jonsen, 1998). 
The critique I propose in this paper is not a critique of 'bioethics', or indeed of bioethicists, but of certain conceptions and framings of enhancement (especially as part of a dichotomy with therapy) as a way of classifying and understanding technologies. Nonetheless, much in the sociological critique of bioethics was and is warranted, if overly broad and totalising in its application. One of the limits of the argument of De Vries et al. (2006) is that within the multiplicity of bioethical accounts, there remains a detectable 'mainstream' (Kelly, 2006) or dominant mode of bioethics drawing primarily on philosophically-informed applied ethics, while other perspectives more amenable to sociological and STS sensibilities often remain marginalised (Hedgecoe, 2004). When, as with the discussion of the problems of dualism in the previous section, I refer to issues with the 'bioethical origins' or the 'bioethical framing' of enhancement I intend it as a critique of the dominant narratives about enhancement and am not trying to suggest that all bioethical perspectives share this limitation.

\section{Case Studies of Enhancement Technologies}

Case studies (rightly) remain a core tool for STS studies. They provide a body of empirical data, something that is often absent from other discussions of enhancement technologies. They also present a means to challenge universalising tendencies (Hedgecoe, 2004) that present all technologies and technological applications labelled as enhancements as merely recurrent examples of the same (moral) problem. A body of STS case studies offers the opportunity to investigate, compare and contrast specific examples of technologies labelled as 'enhancing, drawing out the differences in context, meaning and consequences across cases.
Operationalising the critical agenda described above, case studies should also draw out the normative assumptions contained in the claims and assessments made about enhancement, whether by ethicists, transhumanists or technology developers. These goals can be configured as the following components of an STS programme of investigation:

2) To study how particular technologies have become labelled or classified as being for 'human enhancement' or having 'enhancement applications'.

3) To look at the human characteristics that technologies are supposed to enhance and to ask how and why these characteristics are valued. What is the role of wider cultural, economic and political contexts in making some human traits desirable and others undesirable?

For both questions it is also important to remember that 'enhancement' is often a label applied by experts from outside the domain, such as medicine or sport, where a particular technology is actually deployed in practice. One of the purported successes of institutional and professional bioethics has been its 'ability to import into medicine a set of ethical standards that are not native to the occupational and organizational cultures of medicine itself' (Zussman, 2000: 10 cited in Hedgecoe, 2004: 134). However, in the case of enhancement, it is by no means clear whether the classification of technologies as 'enhancing' or 'therapeutic' has exercised any great influence on contemporary medical thought or practice. Case studies should therefore also seek to uncover how technologies and technological practices labelled as enhancing are understood in their domains of application and whether a 
label of 'enhancement' has any legitimacy or consequences for everyday practice.

A final issue, as identified above, is the tendency towards reductionism and biological determinism in many accounts of enhancement. This is especially true of pro-enhancement accounts where the full range of human capabilities to be enhanced extends to human traits such as sexual identity, morality and aspects of personality like aggression or shyness. Deterministic accounts propose that behaviours are essentially governed by biological, often genetic, factors, while reductionism holds that only these biological factors are worthy of consideration when investigating (human) characteristics. These issues are hardly novel and have already been addressed in relation to claims making in evolutionary psychology (Ehrlich \& Feldman, 2003) and behavioural genetics (Rosoff, 2010). The primary limitation of this type of explanation, when applied to complex human behaviours such as altruism or moral judgement is that, as they become understood as quantifiable outputs of biological functioning, such as changing patterns of brain activity or modulations in gene or biomarker expression, complex behaviours become reified as being only the expression of those variations. Altruism becomes a particular pattern of brain activity; morality becomes a particular pattern of gene expression as the contaminating 'social' is purified to leave only the 'natural'. As a result, concepts such as altruism or morality become 'flattened,' losing any sense of characteristics as internally-experienced episodes of affective reasoning. Accordingly, the fourth component of an STS programme of research on enhancement technologies is:

4) To investigate how complex human characteristics and traits are becoming understood as components of a bio- logical system (the human mind/body), which are amenable to intervention and controlled manipulation through technology.

\section{Is Critique Enough?}

So far I have presented the case for a programme of STS research on enhancement technologies largely in terms of the problematic nature of the existing enhancement debate and the possibilities for STS research to make these limitations explicit. This is certainly within the 'traditional' remit of STS scholarship. Indeed, it may be too close to existing work within STS. Guggenheim and Nowotny (2003) have argued that the STS critique is in danger of becoming repetitive and thereby redundant. For STS scholars there may always be 'further artefacts to deconstruct, and always a new target group which can be enlightened about the flawed nature of prevailing understandings of science' (Woolgar et al., 2009: 10), but to what useful end? This returns to the question of audience. If STS scholarship is mainly directed at other STS scholars or those in related fields then there is relatively little to be gained by colonising the enhancement technologies debate as a further site for 'more of the same' critique (this may even be a reason why there has been relatively little dedicated STS research on enhancement to date).

I would suggest that the extension of STS perspectives and the 'enlightenment' of new target audiences is valuable in itself, but it is potentially limited when presented as critique alone. Critique does not necessarily contain any useful recipe for reforming and constructively improving its targets. We can hardly expect to transform all our audiences into STS scholars and have them abandon all prior convictions. In any case, this would not be especially helpful as it would ignore the limitations of what STS can do 
- for example STS scholarship has largely resisted making normative decisions or adopting a particular politics of technology (Keulartz et al., 2004). A further form of STS work is possible through engagement with new audiences in ways that move beyond deconstruction towards 'positive' and constructive engagement (Latour, 2004). Timmermans \& Berg (2003) advise social scientists to use their expertise to influence the creation and implementation of medical technologies. Similarly, Harry Collins and colleagues (e.g. Collins \& Evans, 2002) have advocated using STS' 'knowledge about knowledge' to advise on the best use of expertise in the public sphere (Woolgar et al., 2009). However, cautionary voices within the field have also warned that a commitment to engagement risks jeopardising STS' cherished potential for (radical) reflexivity.

The case of technological enhancement offers potential avenues and challenges for productive engagement. The aim of this proposed programme of STS research on human enhancement technologies is not in any way a call to try and 'do ethics better than the ethicists.' One productive form of engagement with the bioethics of enhancement might be to use STS case studies of technologies or technological applications labelled as enhancement to contribute to a 'critical bioethics':

Critical bioethics is rooted in empirical research. [...] This does not mean that philosophers have to become social scientists; simply that if they are interested in the ethics of a particular technology, their first port of call should be the social science literature about that technology, rather than the standard bioethics debates (Hedgecoe, 2004: 135-136).

The viability of this approach depends, of course, on the availability of bioethicists willing to collaborate with social scientists and STS practitioners in an endeavour that requires greater reflexivity about the practice and knowledge claims of both bioethics and the natural sciences than is customary in much 'mainstream' bioethics. However, previous attempts to combine STS with potentially compatible ethical traditions such as pragmatism (Keulartz et al., 2004) and the diversity of bioethicists capable of offering a range of perspectives (De Vries et al., 2006) suggest that there is at least potential for such an exercise.

If, as the title of the chapter by Guggenheim and Nowotny (2003) suggests, 'repetition makes the future disappear', then another option for moving beyond critique is for STS to actively re-engage with and contribute to the future. Much of the pro-enhancement literature and almost all the converging technologies agenda deals in future-orientated claims about the transformative (and economically generative) potential of technology. As such, the claims and the rhetorical framing devices of these works are amenable to critical analysis through the sociology of technological expectations (van Lente, 1993; Brown et al., 2000; Borup et al., 2006). Claims about the future potential of enhancement technologies, as with any other form of technological expectation, are intended to convince and enrol relevant actors such as governments, funders and private capital investors in supporting the work needed to try and realise these imagined futures (Brown \& Michael, 2003; Borup et al., 2006). Departing from this approach, a further step for STS scholars would be to engage with Selin's (2008: 1892) ambitious 'sociology of the future'. While the term 'sociology of the future' is not wholly novel, Selin's particular conception describes 'an emerging field of inquiry that works to understand future consciousness drawing from a mix of STS and the practice of foresight' (2008: 1892). 
The suggestion is not that we should all become futurologists, but rather that STS scholars 'should tend to the cultural, political, and economic conditions from which future studies arise' (Selin, 2008: 1889). This approach can ask questions about how legitimacy is created or disputed for future-orientated technological claims, whose expertise counts (and whose is excluded) in making these claims and which groups are envisaged as 'winners' or 'losers' in projected futures. Implicit normative commitments and underlying assumptions - such as the pervasive notion of 'technological progress' - can be laid bare and subject to critical investigation. Such an approach is not without consequences; Selin (2008: 1891) warns: ' $[w]$ hether as a legitimating or destabilizing discourse, the future is a discourse with effects'. By participating in future-orientated discussions, scholars cannot remain 'neutral' and above the debate, but are inevitably drawn in to the politics of the future as their own studies, assessments and evaluations are sucked back into the 'pool' of available ideas about technological futures. What Selin presents as a warning, however, is positively a prescription for those voices in STS advocating a move beyond 'mere' critique. Effects, of the contributory, constructive variety, are exactly what is wanted.

Of course, there remains the danger of social scientists becoming co-opted as allies of particular visions of the future and the actors whose interests these visions serve. The remedy for this must be for social scientists to be continually, reflexively aware of the nature of their own contributions and to reflect on, and perhaps modulate, their work on an ongoing basis. I prefer to look at this positively: engagement with the rhetorical and material enactment of futures does not mean that reflexivity must be set aside in order to make engagement successful, but rather that adequately reflexive engagement is the only acceptable way to proceed. The fifth and final component of an STS agenda for the study of enhancement and enhancement technologies should therefore be:

5) To engage productively, but reflexively, with other disciplines and audiences in reflecting on STS accounts of enhancement and enhancement technologies.

I do not argue that critique is redundant, only that it is not sufficient. It is not an end in itself, but it is a starting point. Critical STS accounts of enhancement and enhancement technologies still need to be carried out to inform our perspectives and generate a body of critical empirical evidence to form a basis for engagement to depart from. The agenda for a critical STS investigation of enhancement and enhancement technologies can be summarised as follows:

1) To map out the changing landscape of the enhancement debate(s) from its bioethical origins to the present converging technologies agenda.

2) To study how particular technologies have become labelled or classified as being for 'human enhancement' or having 'enhancement applications'.

3) To look at the human characteristics that technologies are supposed to enhance and to ask how and why these characteristics are valued. What is the role of wider cultural, economic and political contexts in making some human traits desirable and others undesirable?

4) To investigate how complex human characteristics and traits are becoming understood as components of a bio- 
logical system (the human mind/body), which are amenable to intervention and controlled manipulation through technology?

5) To engage productively, but reflexively, with other disciplines and audiences in reflecting on STS accounts of enhancement and enhancement technologies.

In keeping with this agenda, the next step for this contribution is to begin to map out the changing landscape of the enhancement debate(s) from its bioethical origins to the present converging technologies agenda. Accordingly, the next section will contain the second major element of this paper: a (brief) review of the nature of the debate on enhancement to date.

\section{A Brief History of Human Enhancement Technologies}

What follows is a short history of the bioethical and converging technologies debate on technologies for human enhancement. As Brown \& Michael (2003: 5) remind us, both the future and the past are available to us 'only [...] imaginatively through histories and projections.' Histories are one such form of projection: they are accounts of the past, created and structured in the present, in ways that organise and account for past events that accord with contemporary understandings and purposes (Morrison, 2012). The account I present here is inevitably selective and partial. It is intended to draw attention to those aspects of the enhancement debate that I believe are most relevant to the claims I make in this paper and the issues I have identified as most pertinent for a programme of STS research on enhancement and enhancement technologies. This does not, I believe, diminish its value as long as we remain aware of the contingent and constructed nature of our own texts. Furthermore, this brief account can be used as a starting point for further investigation, including investigation of all the rich bioethical discussion excluded or summarised here.

\section{Genetics and the Origins of Enhancement}

The bioethical concept of human technological enhancement came to prominence through the debates on genetic engineering and gene therapy during the 1970s and 1980s. Much of the discussion at this time was of North American provenance. As the technology to insert 'foreign' or synthetic genetic material into the cells of a host organism began to look scientifically achievable, the bioethical community became increasingly concerned with the ethical considerations of genetic manipulation being applied to human subjects (Crigger, 1998; Martin, 1999). Two core distinctions were developed within the bioethics literature in order to gain moral purchase on the emerging technology (Martin, 1999; Scully \& Rehmann-Sutter, 2001). Firstly, genetic modification at the level of somatic (body) cells was distinguished from alteration of germline (gamete producing) cells on the basis that the former intervention only affects individuals whereas the latter is intended to confer genetic changes that can be passed on to future generations. Secondly, and of greatest import here, the transfer of genes intended to treat existing (genetic) diseases was distinguished as gene therapy, from the genetic modification of humans with the intent of boosting human traits above normal levels or adding wholly new capabilities thereby enhancing the recipient's abilities (Gardner, 1995; Juengst, 1997). Thus, in its inception, the concept of enhancement was defined as one half of a dichotomy with therapy. Importantly, while enhancement is understood as 
distinct from therapy, ultimately it can only be defined by reference to the concept of 'the therapeutic'. As the debate has moved from 'enhancement vs. therapy' to 'antienhancement vs. pro-enhancement', the category of therapy tends to fade from view, but, as I intend to demonstrate in subsequent sections, it still has an important role in framing the terms of discussion.

Returning to the genetic modification debate, the resulting moral verdict at the time was that gene therapy affecting regular (somatic) body cells was ethically acceptable but genetic modification to enhance human abilities or pass on traits to subsequent generations was morally prohibited. What can be inferred from the choice of 'enhancement' and 'therapy' as conceptual tools of classification? One, perhaps Whiggish, reading of the decision is that the enhancement/therapy distinction allowed an ethical steering of the nascent technology along a morally acceptable developmental pathway. Alternatively, it could be noted that the choice to valorise therapy and repudiate enhancement is inherently a conservative one, opting to reinforce the value of what is already known and accepted and problematising the unknown and uncertain. Defining 'therapy' as the proper scope of medicine creates a bounded space for medical practice with implicit, if poorly delineated, boundaries, which renders medicine manageable and unthreatening. Beyond the limits of this (safe) domain is the realm of 'enhancement', characterised by potentially unlimited, but uncertain and nebulous possibilities and risks. The casting of enhancement as morally troubling can be seen as an acknowledgement of the need for adequate reflection on the social consequences of the technological choices made by a given society, but also appears to contain an underlying risk averse, even paternalistic element, relying on tradition as a touchstone to protect society from possible harms of the unknown and uncertain. Viewed another way, the creation of categories of therapy and enhancement creates a sphere of 'pure' use of medicine and medical technologies protected from the 'dangerous' and forbidden realm of unbounded application that is enhancement (after Douglas, 1969). In this, the concept of enhancement is rather different from other theories of medical expansion such as medicalisation, which, in its critical formulation, argues that medicine might not always be the best way to address social problems, but does so on a case-by-case basis, not because it posited that there was or should be an a priori fixed realm of medicine.

Critical accounts of bioethics such as Evans (2002) and Kelly (2006) have argued that, as bioethics has become increasingly institutionalised as a part of the formal regulation of medicine and biotechnology, it has lost its critical distance from those disciplines it is intended to oversee. Instead, it is argued, bioethical review has come to act as a mechanism for diffusing public anxiety about new technological practices, while ultimately legitimising their deployment, by issuing ethical caveats on (and thereby creating) appropriate ways to use them. In this view the role of ethical rhetorical tools such as the enhancement/ therapy dichotomy serve the social function of providing an ethical 'fix' to 'a medical demand to push the limits of medical treatment into new frontiers' (Imber, 2001: 31). Scully \& Rehmann-Sutter (2001) make this argument in relation to gene therapy, reporting that when the enhancement/ therapy dichotomy was proposed, gene therapy was in its infancy and no capacity for enhancement actually existed. Therefore, identifying enhancement as a morally problematic domain to be prohibited did not actually involve any practical loss of a technological option for 
scientists and biotechnology companies, but instead served to initiate the progress of the technology by creating the morally acceptable category of gene therapy, under which the first clinical trials of human gene therapy could be organised.

\section{Enhancement vs. Therapy}

While human genetic modification has remained a more or less constant theme in the enhancement literature, during the 1980s the rhetorical tool of the enhancement/therapy dichotomy began to be applied to other areas of bioethical concern. One of these new cases was the use of human growth hormone (hGH) to increase the growth rates and anticipated adult stature of short children. In 1985 a new form of growth hormone was produced through the techniques of recombinant genetic engineering, which promised potentially 'unlimited' supply of the drug. As growth hormone became more available, the numbers of patients receiving hGH for both traditional diagnostic categories and in experimental applications began to increase significantly, raising concerns about the appropriate use of the drug (Neely \& Rosenfeld, 1994). For bioethicists such as Daniels (1992) and Tauer (1995) the use of hGH in potentially 'normal' short statured children posed questions about the limits and proper scope of medicine and medical technologies that appeared well suited to moral evaluation in terms of enhancement and therapy.

[T] he modification of height, which is possible through administration of biochemical GH, raises the same questions about therapeutic versus enhancement uses of genetics (Tauer, 1995: 18).

This question of limits and boundaries to medical practice is central to the enhancement/therapy dichotomy.
Analysis using the categories of enhancement and therapy soon spread to a range of other practices that threatened (or promised) to blur the boundaries between treating disease and biologically or chemically augmenting 'normal' human behaviours. Many of these, such as cosmetic surgery and the use of pharmaceutical agents to improve the performance of military personnel during combat or athletes during sporting events had been practiced long before the enhancement/ therapy distinction was devised as a tool of academic bioethics. Others, such as the reported use of Ritalin as a study aid by college students or public speakers taking beta blockers to hide flushing whilst performing appeared to fall even more readily into dual 'medical' and 'social' categories of use. Novel cases also emerged, in the form of blockbuster 'lifestyle' pharmaceuticals such as Viagra and Prozac that claimed, in Peter Kramer's (in)famous phrase, to make people 'better than well' (Rothman, 1994; Wright, 1994).

The exercise of moral evaluation was not merely abstract but was, at this point in the debate, intended to serve practical decision making; for example in deciding which aspects of a new intervention should be covered by health insurance. A bioethical evaluation that could separate technological potential into therapeutic and enhancing forms would support an economic decision to cover those applications considered therapeutic and leave the 'enhancing' options as a matter of individuals' ability to pay. Thus, the spread of the enhancement/ therapy dichotomy as an analytic tool can be understood both in terms of its utility to economic and policy imperatives to control healthcare costs and because of its value to professional bioethicists as a specifically ethical form of technological assessment that could be used to colonise 
past, present and future issues of medicine and technological application.

Taking a less instrumental view of academic bioethics, the enhancement/ therapy dichotomy also allows an engagement with traditional philosophical themes of what constitutes a good or worthwhile life. The concerns discussed under the topic of enhancement are multiple, ranging from issues of authenticity and social justice to the question of whether biotechnological interventions have a specific moral character that makes them qualitatively different from 'social' enhancements such as training and education. What is most pertinent to this account, though, is the spread of the label and concept of enhancement to an increasing range of technologies, promoting what might have remained a bioethical modality peculiar to the realm of genetic engineering into a prominent mode of technological classification.

\section{Tools of Classification: From Normal Functioning to 'Beyond Therapy'}

In the case of genetic engineering it had been sufficient to prohibit enhancement at the level of intention to intervene in human biology. Once bioethical attention turned to existing practices where technologies were already in use, the work of classifying particular applications as enhancement or therapy meant that enhancement had to move from being an abstract idea of 'not therapy' to a practically achievable categorisation. In order to make the determination of the boundaries of health (and the corresponding limits of medical practice) a more quantifiable, objective procedure, some early formulations of the dichotomy explicitly drew on prior philosophical attempts to define health and disease in biological and statistical terms, as for example in the work of Christopher Boorse (1977: 542):
[D]iseases are internal states that depress a functional ability below species-typical levels. Health as freedom from disease is then the statistical normality of function, i.e., the ability to perform all typical physiological functions with at least typical efficiency.

This type of thinking, known as the 'normal functioning model', was most prominently championed by ethicist Norman Daniels (1992, 2000; see also Sabin \& Daniels, 1995) who argued that the purpose of medicine is to restore, maintain and compensate for losses in equality of opportunity to individuals that result from disability and disease. The normal functioning model provides a way of calculating the appropriate (moral) boundaries of healthcare expenditure where 'proper healthcare services [...] should be aimed at getting people back to "normal", e.g. restoring an individual's functional capability to the species-typical range for their reference class' (Juengst, 1997: 129).

This type of biostatistical approach exemplifies the strong tendency towards nature/culture dualism in certain formulations of the enhancement/therapy dichotomy. Ignoring the historically and socially contingent nature of medical knowledge, it presumes a single apolitical, ahistorical 'species typical' human body produced through 'value free' biomedical techniques as a universal norm. Moreover the use of normal function models conflates the ideas of statistically 'normality' and the 'natural' human state with all the loaded connotations the latter term implies, leading to the moral validation of normalcy and problematisation of the statistically abnormal as socially undesirable. Normal functioning models of healthcare enjoyed a period of popularity and influence in the enhancement debate. However, it should not be imagined that they ever reflected 
a dominant bioethical consensus: for example Parens (1998) and Juengst (1998) both review a long list of potential objections and problems with normal functioning models ranging from their potential to make seemingly arbitrary decisions about entitlement to medical resources, through to constructionist accounts of medicine that argue that medicine has no a priori boundaries. Even my cursory and selective review of the bioethical origins of enhancement reveals the veracity of Devires et al.'s (2006) claims about the multiplicity of bioethical perspectives.

Recourse to normal functioning approaches has notably declined in recent years. This has largely been due to difficulties in implementation and having to amend the models to ensure that existing, legitimated preventative health measures such as vaccination do not end up being classified as unacceptable 'enhancements', rather than being a result of constructionist or other minority ethical perspectives on 'mainstream' bioethics. It is a measure of the practical complexities of this type of approach that, by 2003 when the U.S. President's Council on Bioethics were ready to launch their major ethical report on enhancement, they opted for the title 'Beyond Therapy?' to reflect the need for debate to go 'not only beyond therapy but also beyond the distinction between therapy and enhancement' (President's Council on Bioethics 2003: 13 emphasis added). Indeed, the debate has changed in ways that bypass much of the difficulty in marking the exact boundary between normal and abnormal, therapy and enhancement, although probably not in ways that would meet with the approval of the distinctly conservative President's Council of 2003.

\section{Pro-enhancement vs. Anti-enhancement}

With the rise of the concept of enhancement, have come pro-enhancement advocates.
Some of these are established voices within bioethics such as professors John Harris and Julian Savalescu. Others, often representing the social and intellectual movement known as transhumanism, come from outside the bioethical community to engage with the moral debates on enhancement (Agar, 2004; Bostrom, 2003). For pro-enhancement moral philosophers, futurists and transhumanists the moral polarity of the original therapy/enhancement dichotomy is reversed: The possibilities of using biotechnology to go beyond the current limits of medicine represents not an ethical transgression, but a desirable opportunity to overcome human limitations, while existing therapeutic applications of technology are at best acceptable and at worst inadequate. The range of enhancement technologies under consideration also expanded, covering more recent pharmaceuticals such as Modafinil which 'enhances wakefulness' (Coveney, 2011), technologies at various stages of development including regenerative medicine, bio-prosthetic devices, cognitive enhancement drugs and neuro-technologies (Hogle, 2005; Miller \& Wilsdon, 2006; Hughes, 2007), and highly speculative future possibilities such as human-machine interfaces, life extension and personality modification (Kurzweil, 2005; Savulescu, 2007).

As the discussion has shifted to pit proand anti-enhancement camps against one another, problematic attempts to devise a quantitative definition of health and illness have been succeeded by a move that places human nature as one of the pivotal concepts at issue between pro- and anti-enhancement advocates. In antienhancement arguments, enhancement transforms human nature through biotechnology and therefore violates it, challenging human identity, and unleashing a range of negative social consequences such as consumer markets in enhancement 
that will exacerbate inequality, and the instrumentalisation of life as people become valued only for the technological capacities they possess. Even though the term 'therapy' is often absent from these discussions, the ghost of the enhancement/ therapy dichotomy can be seen in appeals to human nature. Human nature is, for antienhancement arguments as developed by Sandel (2004) or Fukayama (2002), part of the 'natural': a given state of biological human being which must be respected and protected from hubristic notions of mastery and inappropriate cultural desires to improve upon this natural state. Understood like this, the arguments for human nature are not that far away from the valuation of the (statistical) biological norm as natural and the repudiation of enhancement as an inappropriate cultural desire found in Daniels (1992, 2000).

Pro enhancement advocates also engage with concepts of human nature, refuting the claims of their 'bio-conservative' opponents by questioning the idea that there is a single, pervasive understanding of human nature to discuss in the first place, or that human nature is such that intervention represents a priori an immoral act (Buchanan, 2009; Kaebnick, 2009). Lewens (2009), at least partially echoing the difficulties of maintaining a clear boundary between therapy and enhancement, argues that many accepted interventions such as dental care or vaccination already enhance human capacities beyond the norm with no socially undesirable affects, rendering the idea of human nature as a moral boundary untenable. In many of these cases therapy/ enhancement distinctions become less visible as the technological options they represent become subsumed into a broader set of resources that promote a 'good life' to which individuals and populations are entitled (Savalescu, 2009).
One outcome of the rise of human nature is that the debate appears to become more abstract as it focuses more on the acceptability or repudiation of enhancement en masse via theoretical constructs such as human nature and less on engagement with specific technologies. Additionally, as Ferrari (2008: 2) has argued:

\begin{abstract}
the reduction of the ethical challenges posed by these technologies to the question of human nature has led to a polarization of positions, and has thus generated an impasse from which it is difficult to break free.
\end{abstract}

Why should this apparent semantic stalemate among ethicists concern STS scholars? I suggest a number of reasons. The polarised pro and anti-enhancement framing hides the origins of enhancement as something that took work to distinguish from therapy (however tenuous or problematic that work may have been) and presents enhancement as an unproblematic, established category. The debate comes to position human technological enhancement not only as possible, but as inevitable, where the only thing left to talk about is how to ethically manage the extant or immanent technologies (see for example Baylis \& Robert, 2004). This framing also directly informs much of the converging technologies agenda and is therefore relevant to understand when interrogating that phenomenon.

\section{The Converging Technologies Agenda}

The concept of technological enhancement has spread to become the focus of innovation policy, primarily through the various iterations of the converging technologies (CT) agenda beginning with Roco and Bainbridge's 2003 report 'Converging Technologies for Improving Human Performance: Nanotechnology, 
Biotechnology, Information technology and Cognitive science' and the European response, from the EU High Level Expert Group on the New Technology Wave designated 'Converging Technologies for the European Knowledge Society' (Nordmann, 2004; Ferrari, 2008). Despite a number of differences in content and approach between the US and European articulations of CT (Ferrari, 2008; Fuller, 2009), both retain a core focus on engineering the human - 'enhancing evolution' - to modify individuals and populations to meet the demands of anticipated future social and physical environments.

The concept of convergence invokes currently discrete realms of scientific research and innovation being brought together 'based on the unity of nature' (Roco \& Bainbridge, 2003: ix), to permit a comprehensive engineering of humans as biological systems:

Examples of payoffs will include improving work efficiency and learning, enhancing individual sensory and cognitive capabilities, fundamentally new manufacturing processes and improved products, revolutionary changes in healthcare, improving both individual and group efficiency, highly effective communication techniques including brain-to-brain interaction, perfecting human-machine interfaces including neuromorphic engineering for industrial and personal use, enhancing human capabilities for defense purposes, reaching sustainable development using NBIC tools, and ameliorating the physical and cognitive decline that is common to the aging mind (Roco \& Bainbridge, 2003: 1).

The complete inversion of the original enhancement/therapy dichotomy that accompanies 'pro-enhancement' accounts is clearly visible in the concept of technological convergence. At the same time, the domain of 'therapy' and the accompanying themes of boundaries and limits effectively disappear from the debate. They remain only implicitly, as an existing 'limited' state that enhancement improves upon. 'Nature' remains an acultural, scientifically-given domain ('the unity of nature'), but it is no longer valued as a 'pure' domain to be bounded and protected. Instead the malleability of nature is valorised as a potentially 'boundless' source of biological and economic potential. It is no surprise that the possibilities for human enhancement through converging technologies are closely linked to strategic economic planning, speculative investment, and in particular to discourses of neo-liberal capitalism.

While the nature of 'the good life' to be achieved (or lost) through enhancement has been a topic of debate within previous philosophical accounts, the desirability of enhanced traits within the CT agenda is largely calculated from the perspective of securing economic growth and national (or supranational in the case of the EU) competitive advantage in the global marketplace. The enhanced capacities proposed by the CT agenda itself; faster processing of greater volumes of information, working harder, faster or longer, retaining more data (increased memory capacity) etc., are all essentially improvements in worker efficiency and productivity - key attributes of the ideal neo-liberal citizen-consumer. In this, the CT agenda is doubly neo-liberal in that, as well as promoting human characteristics desirable to neo-liberal representations of the world, it does so by fulfilling the core neo-liberal aim of creating new markets for 'high technology' consumer products and new rounds of innovation. The CT approach to enhancement technologies effectively 
brings human enhancement in to line as another component in the knowledgebased bio-economy, itself a fundamentally neo-liberal enterprise (Birch, 2006).

There are a number of reasons why this might be considered problematic. As described above, neo-liberal ideology favours a particular model of innovation where the desired outputs are marketable products protected by strong intellectual property rights (Birch, 2006; Lave et al., 2010). Such an approach actively militates against innovations that do not require the transformation of social problems into technical ones, that are non-commercial, public rather than private, or where the role of the state is to provide welfare rather than facilitate the expansion of markets, all of which may arguably be more desirable or more appropriate options in a given situation. Abraham (2010) and Moynihan et al. (2002) have identified potentially socially deleterious effects of marketdriven innovation in the pharmaceutical sector, where the creation of new markets sometimes requires the co-promotion of new social problems to which innovative technologies are then presented as the obvious solution.

Birch (2006: 9) also contends that, through the insistence on the inevitably of competition, neoliberalism:

promotes the collapse of a distinction between market value and ethical value so that commercial value becomes the overriding principle for political economy.

Reminding us, if a reminder were needed, not only that economic, political and technological trajectories are inevitably entangled, but that they are also inseparable from ethical considerations and moral and social consequences.
In setting out this account of the human technological enhancement debate, I have tried to highlight key framings and dynamics in how enhancement has been theorised over the past three decades, with the purpose of supporting future STS studies on this topic. Attention to the changing dynamics of enhancement can help future investigators to locate particular case studies in terms of what framing of enhancement they might expect to be dominant for that particular technology at a given time. For example, a historical study of Ritalin use in the 1990s might expect moral debates of the time to be framed in terms of whether prescription for attentiondeficit / hyperactivity disorder (ADHD) is a legitimate therapy or an illicit enhancement, while an investigation of cognitive enhancement drugs currently under development is more likely to encounter ethical discussion of whether modifying cognitive capacity is detrimental or not to human nature. Of course, it is also entirely, and interestingly, possible that studies will find far more nuanced discussions at work, all of which can be usefully fed back to improve and build upon what I have merely sketched out here.

\section{Conclusions}

This program for future STS work in the domain of human enhancement technologies offers an opportunity for contributions from a range of existing theories and perspectives from across the heterogeneous domain of practices loosely aggregated under the title of 'STS scholarship'. Some lines of investigation have already been touched on in the course of the paper: case studies of existing, developing and prospective forms of enhancement technologies potentially animated by a variety of concerns from co-production of technology and society 
around enhancement, to network analysis, the role of professional boundaries and expertise, technological scripting and user perspectives, technological expectations, markets, and economic representations of the world.

Enhancement is also amenable to investigation in terms of innovation policy, regulation, governance and legal frameworks - for example, how are existing interventions labelled as enhancements regulated in different jurisdictions, what strategies are in place for proposed enhancements to deal with current regulatory and governance frameworks - are they drugs, devices, 'advanced medicinal products' or something else? If enhancements are tested on healthy volunteers in post-phase I clinical trials, what definitions of risk or efficacy might be employed, or will clinical trials even remain the 'gold standard' for assessing enhancement products? What might a future governance landscape look like? Where do enhancement technologies sit in terms of upstream public engagement, or responsible innovation?

Work is also needed on whether technological enhancement is an inherently Western concept or whether it translates across other cultures, and if so how and with what reconfigurations and effects? Anthropological approaches can be especially suited to studying how value schema other than Western bioethics might shape the governance of technologies labelled as enhancements (cf. Sleeboom-Faulkner, 2011 on regenerative medicine in Japan). Ultimately, all of these approaches are intended to contribute to a deeper STS understanding (and theorising) of enhancement technologies as a phenomenon and as a concept. That is not, of course to say that they should come together to form a new 'grand narrative' of enhancement. Rather, findings from a range of STS studies can accumulate to yield iterative and multiple accounts, encompassing the discontinuities and contradictions inherent in the topic as well as the continuities and connections.

The importance of productive futureorientated activities in STS has also been emphasised. There are more possibilities than can be sketched here: One desirable goal would be to produce nuanced discussions of potential technological futures that avoid the utopias and dystopias of certain existing considerations of enhancement. It could be highly productive to develop STS-informed scenario planning or foresight activities around enhancement technologies. Such anticipatory discourses could be used to explore future development of enhancement technologies under different regulatory and economic conditions, for example as public goods rather than marketable products. The point here is not to 'get the future right' or, necessarily, to reduce uncertainty, but to provoke useful discussion and debate.

Finally, a programmatic study of enhancement technologies offers STS scholars the opportunity to explore different articulations of 'progress' encoded in debates around enhancement and ultimately to relate the narrow discussion of contemporary 'biotechnological' enhancement to the older, broader concepts of social enhancement set out at the beginning of this article.

\section{References}

Abraham J (2010) Pharmaceuticalization of society in context: Theoretical, empirical and health dimensions. Sociology 44(4): 603-622.

Academy of Medical Sciences British Academy Royal Academy of Engineering \& Royal Society (2012) Human enhancement and the future of work: 
Report from a joint workshop hosted by the Academy of Medical Sciences, the British Academy, the Royal Academy of Engineering and the Royal Society. Available at: www.britac.ac.uk/policy/ Human-enhancement.cfm (Accessed 10 November 2012).

Agar N (2004) Liberal eugenics: in defence of human enhancement. Oxford: Blackwell.

Ashcroft RE (2003) American biofutures: Ideology and utopia in the Fukuyama/ Stock debate. Journal of Medical Ethics 29: 59-62.

Banse G Grunwald A Hronszky I \& Nelson G (eds) (2007) Assessing Societal Implications of Converging Technological Development. Berlin: Edition Sigma.

Baylis F \& Robert JS (2004) The Inevitability of Genetic Enhancement Technologies. Bioethics 18(1): 1-26.

Bijker WE Pinch TJ \& Hughes TP (eds) (1987) The social construction of technological systems: new directions in the sociology and history of technology. Cambridge, MA: MIT Press.

Birch K (2006) The Neoliberal Underpinnings of the Bioeconomy: The Ideological Discourses and Practices of Economic Competitiveness. Genomics, Society and Policy 2: 1-15.

Boorse C (1977) Health as a Theoretical Concept. Philosophy of Science 44(4): 542-573.

Borup M Brown N Konrad K \& Van Lente $\mathrm{H}$ (2006) The Sociology of Expectations in Science and Technology. Technology Analysis \& Strategic Management 18: 285-98.

Bostrom N (2003) Human Genetic Enhancements: a Transhumanist Perspective. The Journal of Value Enquiry 37: 493-506.

Brown N \& Michael M (2003) A Sociology of Expectations: Retrospecting Prospects and Prospecting Retrospects. Technology Analysis \& Strategic Management 15(1): 3-18.
Brown N Rappert B \& Webster A (eds) (2000) Contested Futures: A Sociology of Prospective Techno-Science. Aldershot: Ashgate.

Buchanan A (2009) Human Nature and Enhancement. Bioethics 23(3): 141-150.

Collins HM \& Evans R (2002) The Third Wave of Science Studies: Studies of Expertise and Experience. Social Studies of Science 32(2): 235-96.

Conrad P \& Potter D (2004) Human Growth Hormone and the Temptations of Biomedical Enhancement. Sociology of Health \& Illness 26(2): 184-215.

Conrad P (2005) The Shifting Engines of Medicalization. Journal of Health and Social Behavior 46(1): 3-14.

Coveney CM (2010) Awakening Expectations: Exploring the Social and Ethical Issues Surrounding the Medical and Non-Medical Use of Sleep Drugs in the UK. Unpublished Doctorate. Nottingham: University of Nottingham.

Coveney CM (2011) Exploring Modafinil Use in Social Context. In: Pickersgill MD \& Van Keulen I (eds) Sociological Reflections on Neuroscience. Bingley: Emerald, 203-228.

Crigger B-J (1998) As Time Goes by: An Intellectual Ethnography of Bioethics. In: De Vries R \& Subedi J (eds) Bioethics and Society: Constructing the Ethical Enterprise. Upper Saddle River, N. J: Prentice Hall, 192-215.

Daniels N (1992) Growth Hormone Therapy for Short Stature: Can We Support the Treatment/Enhancement Distinction. Growth, Genetics and Hormones 8(1 supplement): S46-S48.

Daniels N (2000) Normal Functioning and the Treatment-Enhancement Distinction. Cambridge Quarterly of Healthcare Ethics 9(3): 309-322.

De Melo-Martin I (2005) Firing Up the Nature/Nurture Controversy: Bioethics and Genetic Determinism. Journal of Medical Ethics 31: 526-530. 
De Vries R Turner L Orfali K \& Bosk C (2006) Social Science and Bioethics: the Way Forward. Sociology of Health \& Illness 28(6): 665-677.

Dickenson D (2013) Me Medicine vs. We Medicine: Reclaiming Biotechnology for the Common Good. New York: Columbia University Press.

Douglas M (1969) Purity and Danger: an Analysis of Concepts of Pollution and Taboo. Revised edition. London: Routledge \& Kegan Paul.

Ehrlich P \& Feldman M (2003) Genes and Cultures: What Creates our Behavioural Phenome? Current Anthropology 44(1): 87-107.

Evans JH (2002) Playing God? Human Genetic Engineering and the Rationalization of Public Bioethical Debate. Chicago, IL: University of Chicago Press.

Ferrari A (2008) Is It All about Human Nature? Ethical Challenges of Converging Technologies Beyond a Polarized Debate. Innovation: The European Journal of Social Science Research 21(1): 1-24.

Fuller S (2009) Knowledge Politics and New Converging Technologies: a Social Epistemological Perspective. Innovation: The European Journal of Social Science Research 22(1): 7-34.

Fuller S (2011) Humanity 2.0: What It Means to Be Human: Past, Present and Future. Basingstoke: Palgrave Macmillan.

Fukayama F (2002) Our Post-Human Future: Consequences of the Biotechnology Revolution. New York: Ferrar, Straus \& Giroux.

Gardner W (1995) Can enhancement be prohibited? Journal of Medicine and Philosophy 20: 65-84.

Guggenheim M \& Nowotny H (2003) Joy in Repetition Makes the Future

Disappear: A Critical Assessment of the Present State of STS. In: Joerges B \& Nowotny H (eds) Social Studies of Science and Technology: Looking Back, Ahead. Dordrecht: Kluwer, 229-58.
Hedgecoe AM (2004) Critical Bioethics: Beyond the Social Science Critique of Applied Ethics. Bioethics 18(2): 120-143.

Hogle LF (2005) Enhancement Technologies and the Body. Annual Review of Anthropology 34: 695-716.

Hughes JJ (2007) The struggle for a smarter world. Futures 39(8): 942-954.

Imber J (1998) Medical Publicity Before Bioethics: Nineteenth-Century Illustrations of Twentieth-Century Dilemmas. In: De Vries R \& Subedi J (eds) Bioethics and society: constructing the ethical enterprise. Upper Saddle River, N.J: Prentice Hall, 16-37.

Juengst ET (1997) Can Enhancement Be Distinguished from Prevention in Genetic Medicine? Journal of Medicine and Philosophy 22(2): 125-142.

Juengst ET (1998) What Does Enhancement Mean? In: Parens E (ed) Enhancing Human Traits: Ethical and Social Implications. Washington, D. C.: Georgetown University Press, 29-47.

Jonsen AR (1998) The Birth of Bioethics. New York: Oxford University Press.

Kass LR (2003) Ageless Bodies, Happy Souls: Biotechnology and the Pursuit of Perfection. The New Atlantis 1 (Spring): 9-28.

Kaebnick GE (2009) “It's against nature”. Hastings Center Report 39(1): 24-6.

Kelly SE (2006) Towards and Epistemological Luddism of Bioethics. Science Studies 19(1): 69-82.

Keulartz J Schermer M Korthals M \& Swierstra T (2004) Ethics in Technological Culture: a Programmatic Proposal for a Pragmatist Approach. Science, Technology \& Human Values 29(1): 3-29.

Kurzweil R (2005) Human 2.0. New Scientist 187(2518): 32-37.

Latour B (2004) Why Has Critique Run Out of Steam? From matters of Fact to Matters of Concern. Critical Inquiry 30(2): 22548. 
Latour B (1993) We Have Never Been Modern. Southampton: Harvester Wheatsheaf.

Lave R Mirowsky P \& Sandells R (2010) Introduction: STS and Studies of Neoliberal Science. Social Studies of Science 40(5): 659-675.

Lewens T (2009) Enhancement and Human Nature: The Case of Sandel. Journal of Medical Ethics 35: 354-356.

MacKenzie D (1990) Inventing Accuracy: A Historical Sociology of Nuclear Missile Guidance. Cambridge, MA: MIT Press.

MacKenzie D \& Wajcman J (eds) (1999) The Social Shaping of Technology (2nd edition). Maidenhead: Open University Press.

Martin PA (1999) Genes as Drugs: the Social Shaping of Gene Therapy and the Reconstruction of Genetic Disease. Sociology of Health \& Illness 21(5): 517538.

Mills C (2010) Editorial: Continental Philosophy and Bioethics. Bioethical Inquiry 7: 145-148.

Miller P \& Wilsdon J (2006) Better Humans? The Politics of Human Enhancement and Life Extension. London: Demos.

Morrison M (2008) Beyond therapy? Investigating biomedical enhancement in the case of human growth hormone. Unpublished Doctorate. Nottingham: University of Nottingham.

Morrison M (2012) Promissory futures and possible pasts: The dynamics of expectations in regenerative medicine. BioSocieties 7: 3-22

Moynihan R Heath I \& Henry D (2002) Selling Sickness: the Pharmaceutical Industry and Disease Mongering. British Medical Journal 324(7342): 886-890.

Nichter M \& Vuckovic N (1994) Agenda for An Anthropology of Pharmaceutical Practice. Social Science \& Medicine 39(11): 1509-1525.
Nordmann A (rapporteur) (2004) Converging Technologies: Shaping the Future of European Societies. Report of the European Commission High Level Expert Group (HLEG) on Foresighting the New Technology Wave. Available from at: ec.europa.eu/research/ conferences/2004/ntw/pdf/final_report_ en.pdf (Accessed 9 January 2010).

Nordmann A (2009) Tomorrow's People, Today's Challenge. In: Healey $\mathrm{P}$ \& Rayner S (eds) Unnatural Selection: The Challenges of Engineering Tomorrow's People. London: Earthscan, 25-31.

Neely KE \& Rosenfeld RG (1994) Use and Abuse of Human Growth Hormone. Annual Review of Medicine 45: 407-420.

Oxford English Dictionary (OED) Online. Enhance, v. Oxford University Press. Available at: www.oed.com/view/En try/62342? redirectedFrom=enhance (Accessed 3 June 2013).

Parens E (1998) Is Better Always Good? The Enhancement Project. In: Parens E (ed) Enhancing Human Traits: Ethical and Social Implications. Washington, D.C.: Georgetown University Press, 1-28.

President's Council (US) (2003) Beyond Therapy? Biotechnology and the Pursuit of Happiness. Washington: Dana Press.

Rappert B (2007) Biotechnology, Security and the Search for Limits: An Inquiry into Research and Methods. Basingstoke: Palgrave Macmillan.

Roco MC (2008) Possibilities for Global Governance of Converging Technologies. Journal of Nanoparticle Research 10(1): 11-29.

Roco MC \& Bainbridge WS (eds) (2003) Converging Technologies for Improving Human Performance: Nanotechnology, Biotechnology, Information Technology and Cognitive Science. Dordrecht: Kluwer Academic Publishers. 
Roco M C \& Bainbridge WS (2013) The New World of Discovery, Invention, and Innovation: Convergence of Knowledge, Technology, and Society. Journal of Nanoparticle Research 15(9): 1946.

Rosoff PM (2010) In: Search of the Mommy Gene: Truth and Consequences in Behavioural Genetics. Science, Technology \& Human Values 35(2): 200243.

Rothman DJ (1994) The Problem with Cosmetic Psychopharmacology - Shiny Happy People. New Republic 210(7): 3438.

Sabin J \& Daniels N (1995) Determining 'Medical Necessity in Mental Health Practice. Hastings Center Report 24: 5-13. Sandel MJ (2004) The Case Against Perfection: What's Wrong with Designer Children, Bionic Athletes, and Genetic Engineering? The Atlantic Monthly 293(3): 50-62.

Savulescu J (2007) Genetic Interventions and the Ethics of Enhancement of Human Beings. In: Steinbock B (ed) The Oxford Handbook of Bioethics. Oxford: Oxford University Press, 516-535.

Savalescu J (2009) Enhancement and Fairness (updated version). Available at: www.bep.ox.ac.uk/_data/assets/pdf_ file/0019/9361/Updatedversion120308. pdf (Accessed 4 August 2014).

Science and Technology Options Assessment (STOA) (2006) Converging Technologies in the 21st century: Heaven, Hell or Down to Earth? Available at: www.europarl.europa. eu/stoa/cms/home/publications/ studies? year $=2006 \& q=\&$ studies search=Submit+Query (Accessed 5 August 2013).
Science and Technology Options Assessment (STOA) (2012) Making Perfect Life: European Governance Challenges in 21st Century Bio-engineering. Available at: www.europarl.europa. $\mathrm{eu} / \mathrm{stoa} / \mathrm{cms} / \mathrm{home} / \mathrm{publications/}$ studies? year $=2012 \& \mathrm{q}=\&$ studies search=Submit+Query (Accessed 5 August 2013).

Scully JL \& Rehmann-Sutter C (2001) When Norms Normalize: The Case of Genetic Enhancement. Human Gene Therapy 12(1): 87-95.

Selin C (2008) The Sociology of the Future: Tracing Stories of Technology and Time. Sociology Compass 2: 1878-1895.

Sleeboom-Faulkner M (2011) Regulating cell lives in Japan: avoiding scandal and sticking to nature. New Genetics \& Society 30(3): 227-240.

Tauer CA (1995) Human Growth Hormone: A Case Study in Treatment Priorities. Hastings Center Report 25(3 - special supplement): S18-S20.

Timmermans S \& Berg M (2003) The Practice of Medical Technology. Sociology of Health \& Illness 25(3): 97-114.

Twine R (2005) Constructing Critical Bioethics by Deconstructing Culture / Nature Dualism. Medicine, Healthcare and Philosophy 8: 285-295.

Van Lente H (1993) Promising Technology: The Dynamics of Expectations in Technological Developments. Enschede, NL: Proefschrift Universiteit Twente.

Wailoo K (2007) Old Story, Updated: Better Living Through Pills. New York Times $13^{\text {th }}$ November 2007. Available at: www. nytimes.com/2007/11/13/health/13essa. html?_r=0 (Accessed 14 January 2014).

Woolgar S Coopmans C \& Neyland D (2009)

Does STS Mean Business? Organization 16(1): 5-30.

Wright R (1994) The Coverage of Happiness: When Prozac Meets Universal Coverage. New Republic 210(11): 24-29. 
Zussman R (2000) The Contribution of Sociology to Medical Ethics. Hastings Center Report 30: 7-11.

\section{EU Framework Program 6 projects:}

DEEPEN - Deepening Ethical Engagement and Participation in Emerging Nanotechnologies. Project information available at: cordis.europa.eu/projects/ rcn/84695_en.html

ENHANCE - Enhancing Human Capacities: Ethics, Regulation and European Policy. Project information available at: cordis.europa.eu/projects/index. cfm?fuseaction=app.details\&TXT $=\mathrm{ENH}$ $\mathrm{ANCE} \& \mathrm{FRM}=1 \& \mathrm{STP}=10 \& \mathrm{SIC}=\& \mathrm{PGA}=$ $\mathrm{FP} 6 \& \mathrm{CCY}=\& \mathrm{PCY}=\& \mathrm{SRC}=\& \mathrm{LNG}=\mathrm{en} \& \mathrm{R}$ $\mathrm{EF}=75601$

\section{EU Framework Programme 7 projects:}

EPOCH - Ethics in Public Policy making: The Case of Human Enhancement. Project information available at: cordis.europa. eu/projects/rcn/96892_en.html

ETHENTECH - Ethics of Enhancement Technology. Project information available at: cordis.europa.eu/projects/rcn/92742_ en.html

FABRICED - French and British Contemporary Ethical Debates on Human Enhancement: Building Dialogue and Shared Vocabulary. Project information available at: cordis.europa.eu/projects/ rcn/99853_en.html
Michael Morrison

Centre for Health, Law and Emerging

Technologies (HeLEX)

Nuffield Department of Population Health

University of Oxford

Old Road Campus

Headington

Oxford OX3 7LF

UK

Email: michael.morrison@dph.ox.ac.uk 